\title{
Size of the fracture process zone in high-strength concrete at a wide range of loading rates
}

\author{
R. C. Yu, X. X. Zhang ${ }^{1}$, G. Ruiz, M. Tarifa and M. Cámara \\ Universidad de Castilla-La Mancha, 13071 Ciudad Real, Spain \\ zhangxiaoxinhrb@gmail.com
}

Keywords: Fracture process zone, loading rate, high-strength concrete

\begin{abstract}
Compared with the extensive research on properties of the fracture process zone (FPZ) under quasi-static loading conditions, much less information is available on its dynamic characterization, especially for high-strength concrete (HSC). This paper presents the very recent results of an experimental program aimed at disclosing the loading rate effect on the size and velocity of the (FPZ) in HSC. Eighteen three-point bending specimens were conducted under a wide range of loading rates from from $10^{-4} \mathrm{~mm} / \mathrm{s}$ to $10^{3} \mathrm{~mm} / \mathrm{s}$ using either a servo-hydraulic machine or a self-designed drop-weight impact device. Four strain gauges mounted along the ligament of the specimen were used to measure the FPZ size. Surprisingly, the FPZ size remains almost constant (around $20 \mathrm{~mm}$ ) when the loading rate varies seven orders of magnitude.
\end{abstract}

\section{Introduction}

For cementitious materials, the inelastic zone around a crack tip is denoted as the Fracture Process Zone. The extention and location of the FPZ is often dominated by complicated mechanisms, such as micro-cracking, crack bridge and friction. Due to the close relationship between the FPZ size and the characteristic length of a material, the FPZ evolution under different loading conditions has been the object of countless research efforts for decades [1-4].

In the present work, we chose the strain-gauge technology to measure the FPZ size in HSC at a wide range of loading rates, from $10^{-4} \mathrm{~mm} / \mathrm{s}$ to $10^{3} \mathrm{~mm} / \mathrm{s}$. Two testing devices, a hydraulic servo-controlled testing machine and a self-designed drop-weight impact device were adopted. Furthermore, the detailed information from the strain history records will undoubtedly facilitate the validation of numerical models aimed at disclosing rate dependency.

\section{Experimiental procedure}

Material characterization. A single HSC was used throughout the experiments, made with porphyry aggregates of $12 \mathrm{~mm}$ maximum size and ASTM type IV cement, I42.5L/SR. Micro silica-fume slurry and super plasticizer (Glenium ACE 325, B255) were added to the concrete composition. The mixing proportions by weight were 1:0.336:3.52:1.62:0.3:0.043 (cement: water: coarse aggregate: sand: micro-silica fume slurry: super plasticizer).

Compressive tests were conducted according to ASTM C39 and C469 on $75 \mathrm{~mm} \times 150 \mathrm{~mm}$ (diameter $\times$ height) cylinders. Brazilian tests were also carried out using cylinders of the same dimensions and following the procedures recommended by ASTM C496. Eight cylinders were cast, four for compressive tests and four for splitting tests. The mechanical properties as determined from various characterization and control tests are shown in Table 1.

Three-point-bend fracture tests. As aforementioned, in order to study the loading-rate effect in HSC, three-point bending tests on notched beams were conducted over a wide range of loading rates, from $10^{-4} \mathrm{~mm} / \mathrm{s}$ to $10^{3} \mathrm{~mm} / \mathrm{s}$. Two testing apparatus were employed, one was a hydraulic servo-controlled testing machine, the other was a self-designed drop-weight impact instrument. The beam dimensions were $100 \mathrm{~mm} \times 100 \mathrm{~mm}(\mathrm{~B} \times \mathrm{D})$ in cross section (beam width and depth), and 420 $\mathrm{mm}$ in total length $\mathrm{L}$. The initial notch-depth ratio $a_{0} / D\left(\mathrm{a}_{0}\right.$ : initial notch length) was approximately 
0.5 , and the span $\mathrm{S}$ was fixed at $300 \mathrm{~mm}$ during the tests, see Figure 1. Each specimen was removed from the moist room one day before the test and restored to the chamber after bonding the strain gauges. The specimen surface was polished and all four strain gauges (SG01-SG04, Model: LY 11 6/120A, $6 \mathrm{~mm}$ in length and $2.8 \mathrm{~mm}$ in width) were bonded to that surface, with a distance of $10 \mathrm{~mm}$ between each neighbouring gauge. Since a running crack in concrete is often deflected by aggregates along its path, the four strain gauges were bonded $10 \mathrm{~mm}$ apart from the centerline of the beam, see Figure 1. Those strain gauges provided not only the strain history at the bonded positions, but also the time at which the crack tip of the FPZ passed each strain gauge.

\begin{tabular}{|c|c|c|c|c|c|}
\hline & $\begin{array}{c}f_{c} \\
{[\mathrm{MPa}]}\end{array}$ & $\begin{array}{c}f_{t} \\
{[\mathrm{MPa}]}\end{array}$ & $\begin{array}{c}G_{F} \\
{[\mathrm{~N} / \mathrm{m}]}\end{array}$ & $\begin{array}{c}E \\
{[\mathrm{GPa}]}\end{array}$ & $\begin{array}{c}\rho \\
{\left[\mathrm{kg} / \mathrm{m}^{3}\right]}\end{array}$ \\
\hline Mean & 102.7 & 5.4 & 141 & 31 & 2368 \\
\hline $\begin{array}{c}\text { Std. } \\
\text { Dev. }\end{array}$ & 2 & 0.8 & 9 & 2 & 1 \\
\hline
\end{tabular}

(Note: $f_{c}$ : compressive strength; $f_{t}:$ indirect tensile strength; $G_{F}:$ fracture energy; E: elastic modulus; $\rho$ : density)

Table 1: Mechanical and fracture properties of the HSC tested.

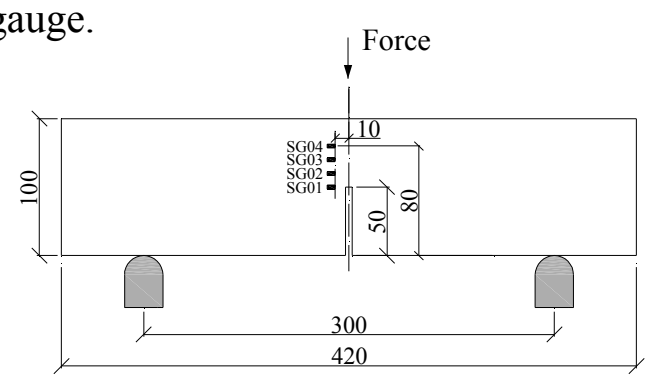

Figure 1:Specimen with bonded strain gauges (units in $\mathrm{mm}$ ).

Tests under loading rates from $10^{-4} \mathrm{~mm} / \mathrm{s}^{\text {to }} 10^{1} \mathrm{~mm} / \mathrm{s}$. The tests were performed employing the hydraulic servo-controlled testing machine under position control. Three loading rates, from quasi-static level $\left(5.50 \times 10^{-4} \mathrm{~mm} / \mathrm{s}\right)$ to rate dependent levels $(0.55 \mathrm{~mm} / \mathrm{s}$ and $17.4 \mathrm{~mm} / \mathrm{s})$, were applied. Three specimens were tested at each loading rate.

Tests under loading rates from $10^{2} \mathrm{~mm} / \mathrm{s}$ to $10^{3} \mathrm{~mm} / \mathrm{s}$. All tests were conducted using the instrumented, drop-weight impact apparatus, which was designed and constructed in the Laboratory of Materials and Structures at the University of Castilla-La Mancha. More details are given in reference [5]. The apparatus was employed to drop from three heights 40, 160 and $360 \mathrm{~mm}$. The corresponding impact speeds were $8.81 \times 10^{2} \mathrm{~mm} / \mathrm{s}, 1.76 \times 10^{3} \mathrm{~mm} / \mathrm{s}$ and $2.64 \times 10^{3} \mathrm{~mm} / \mathrm{s}$, respectively. Three specimens were tested at each impact speed. A detailed description of the instrument is given in reference [6].

Crack-velocity measurement. When the fracture initiates, an unloading stress wave is generated and travels to the strain gauge, the sudden decrease of strain as a function of time indicates the crack initiation, see Figure 2 for a typical strain history record from one of the four strain gauges.

The crack velocity naturally refers to the speed in which this initiated cohesive crack tip, i,e. the FPZ front, will propagate. The time interval $t_{f}$ is the crack initiation time. Additionally shown in Figure 2 are $t_{\varepsilon \max }$ and $t_{\varepsilon r 0}$, which indicate the time at peak strain and the time at which the strain is relaxed to zero, respectively. We define the time interval between $t_{\varepsilon \max }$ and $t_{\varepsilon r 0}$ as the strain relaxation time $t_{r}$.

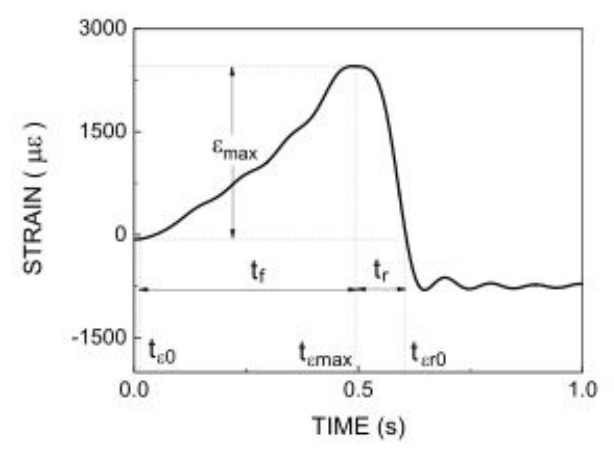

Figure 2: A typical strain versus time curve (shown in the record of SG01), taking the example of the loading rate at $0.55 \mathrm{~mm} / \mathrm{s}$.

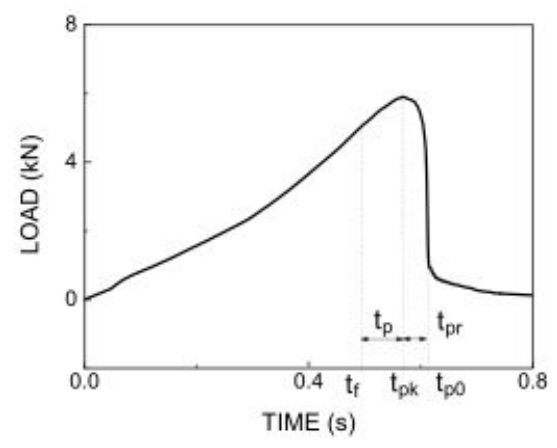

Figure 3: The typical load history for low loading rates, taking example of $0.55 \mathrm{~mm} / \mathrm{s}$. 
Since the stress wave speed is much greater than the crack propagation velocity [7], the time taken by the unloading stress wave to propagate from the crack line to SG0n (the offset distance from the center line is $10 \mathrm{~mm}$ ) need not be taken into account. Thus an average crack-velocity between two neighboring strain gauges can be obtained through dividing the distance in between-10 mm- by the time interval across the two corresponding peak signals recorded.

Furthermore the peak load is also an important parameter, which reflects the loading capacity of a given structural element, in our case, a three-point-bend beam, consequently all the information related to the peak load is also essential. In Figure 3, we give all the peak-load related information in one typical load history curve for low loading rate. The terms $t_{p}$ and $t_{p r}$ are defined as the pre- and post-peak crack propagation time. The elapsed time between $t_{\max }$ at SG04 and $t_{p 0}$ is used to obtain the crack velocity along the last $20 \mathrm{~mm}$ where no strain gauge was bonded. In addition, knowing the crack length at peak load $a_{p}$, the pre- and post-peak crack propagation velocity $v_{1}$ and $v_{2}$ are also calculated as $a_{p} / t_{p}$ and $\left(D-a_{0}-a_{p}\right) / t_{p r}$ respectively and given in the next section.

FPZ measurement. Hillerborg et al. [8] first proposed a fictitious crack model for fracture of concrete as shown in Fig. 4. In this model the newly formed crack surfaces and the corresponding fracture process zone are simply simulated by a cohesive zone located in the front of the initial crack tip. As a result, the energy dissipation can be represented by a material-specific cohesive law within the FPZ.

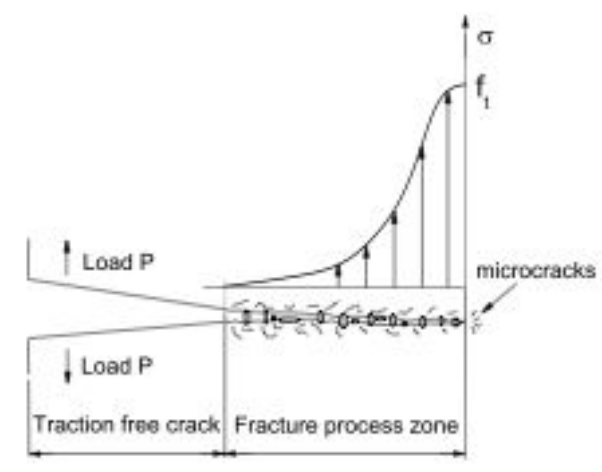

Figure 4. Sketch of concrete crack and FPZ

Here, we explore the advantage of the strain-gauge technology, having in mind that the attainment of peak strain signals, the passing of a cohesive tip, and strain values relaxed to zero represent a traction-free crack tip.

\section{Results and discussion}

The measured load histories are depicted in Figure 5. It needs to be pointed out that under high loading rates, the load refers to the impact force, i.e., the inertial force is also included.

Information related to the peak load, such as the dynamic increase factor (DIF), the time intervals $t_{p k}, t_{p}$ and $t_{p r}$ are reported in Table 2 . The measured velocities $v_{s g}$, the pre- and post-peak crack propagation velocities $v_{1}$ and $v_{2}$ are all listed in Table 3.

Loading rate effect on peak loads. From Figure 5, note that the peak load increases proportionally with the loading rate, such rate effect is minor at low loading rates while it is pronounced at high loading rates. We define the dynamic increase factor (DIF) as the ratio of peak load and its corresponding quasi-static value $\left(5.50 \times 10^{-4} \mathrm{~mm} / \mathrm{s}\right.$ in this case $)$. The DIF for peak loads are 1.4 and 25.0 , for the loading rates of $17.4 \mathrm{~mm} / \mathrm{s}$ and $2.64 \times 10^{3} \mathrm{~mm} / \mathrm{s}$, respectively. In other words, the DIF at high loading rates is approximately one order higher than that at low loading rates. 
It also needs to be pointed out that in Figure 5 (bottom row), we have scaled the load-axis by a factor proportional to its loading rate. Note that the peak load increases slightly faster than its loading rate. This is mainly due to the significant increase of inertia forces, see [9].

It is noteworthy that, at low loading rates, when the load peak is achieved, the crack length $\left(a_{p}\right.$, notch length not included) increased from $10 \mathrm{~mm}$ and $4 \mathrm{~mm}\left(5.5 \times 10^{-4}\right.$ and $\left.5.5 \times 10^{1} \mathrm{~mm} / \mathrm{s}\right)$ to $37 \mathrm{~mm}$ $(17.4 \mathrm{~mm} / \mathrm{s})$; while at high loading rates, the crack length varied from between 5 to $14 \mathrm{~mm}$ for all three cases, see Table 2. In particular, for the loading rate of $17.4 \mathrm{~mm} / \mathrm{s}$, when the peak load is achieved at $t_{p k}$ of $21 \mathrm{~ms}, \mathrm{SG} 02$ is deformation free at $t_{r r 02}$ of $19.9 \mathrm{~ms}$, this shows the first $10-\mathrm{mm}$ stretch from the notch tip is already traction free.
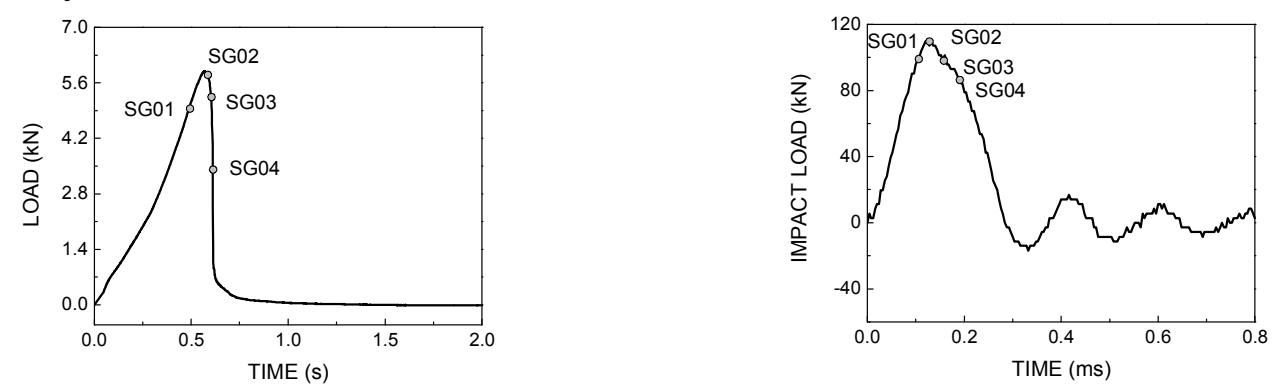

Figure 5: Load history for low loading rate (left): $0.55 \mathrm{~mm} / \mathrm{s}$, and high loading rate (right): $2.64 \times 10^{3} \mathrm{~mm} / \mathrm{s}$, where SG0n marks the time at which the strain peak is obtained for strain gauge SG0n $(n=1,2,3,4)$. Note that for each graph, the load-axis is proportionally scaled to its loading rate.

\begin{tabular}{|c|c|c|c|c|c|c|c|c|}
\hline Loading rate & Peak load & $D I F$ & $t_{f}$ & $t_{p k}$ & $t_{p}\left(t_{p k}-t_{f}\right)$ & $t_{p 0}$ & $t_{p r}\left(t_{p 0^{-}} t_{p k}\right)$ & $a_{p}$ \\
\hline$[\mathrm{mm} / \mathrm{s}]$ & {$[k N]$} & & {$[\mathrm{s}]$} & {$[\mathrm{s}]$} & {$[\mathrm{s}]$} & {$[\mathrm{s}]$} & {$[\mathrm{s}]$} & {$[\mathrm{mm}]$} \\
\hline $5.5 \times 10^{-4}$ & 4.4 & 1.0 & 432 & 494 & 62 & 512 & 18 & 10 \\
\hline$[\mathrm{mm} / \mathrm{s}]$ & {$[k N]$} & - & {$[\mathrm{ms}]$} & {$[\mathrm{ms}]$} & {$[\mathrm{ms}]$} & {$[\mathrm{ms}]$} & {$[\mathrm{ms}]$} & {$[\mathrm{mm}]$} \\
\hline $5.5 \times 10^{-1}$ & 5.9 & 1.3 & 490 & 567 & 77 & 614 & 47 & 4 \\
\hline $1.74 \times 10^{1}$ & 6.3 & 1.4 & 15.8 & 21 & 5.2 & 23.8 & 2.8 & 37 \\
\hline$[\mathrm{mm} / \mathrm{s}]$ & {$[k N]$} & - & {$[\mu \mathrm{s}]$} & {$[\mu \mathrm{s}]$} & {$[\mu \mathrm{s}]$} & {$[\mu \mathrm{s}]$} & {$[\mu \mathrm{s}]$} & {$[\mathrm{mm}]$} \\
\hline $8.81 \times 10^{2}$ & 30.3 & 6.9 & 168 & 200 & 32 & 428.5 & 228.5 & 11 \\
\hline $1.76 \times 10^{3}$ & 63.4 & 14.4 & 128 & 172 & 44 & 331.0 & 159 & 14 \\
\hline $2.64 \times 10^{3}$ & 109.9 & 25.0 & 108 & 120 & 12 & 284 & 164 & 5 \\
\hline
\end{tabular}

Loading rate effect on crack velocity. The crack velocities are listed in Table 3 . In the low loading rate range, on the one hand, for each loading rate, the crack advances with increasing speed; on the other hand, as the loading rate increases, the crack velocity increases proportionally. For instance, at $5.5 \times 10^{-4} \mathrm{~mm} / \mathrm{s}$, the crack velocity increased by a factor of 38 from $0.19 \mathrm{~mm} / \mathrm{s}$ for $v_{s g 1}$ to $7.3 \mathrm{~mm} / \mathrm{s}$ for $v_{s g 3}$; while at the loading rate of $2640 \mathrm{~mm} / \mathrm{s}$, the crack speed varied from $417 \mathrm{~m} / \mathrm{s}$ to $387 \mathrm{~m} / \mathrm{s}$. When the loading rate increased by a factor of 1000 (from $5.5 \times 10^{-4} \mathrm{~mm} / \mathrm{s}$ to $0.55 \mathrm{~mm} / \mathrm{s}$ ), the first-stage crack velocity $v_{s g 1}$ increased by 4100 , while the late-stage velocities $v_{s g 3}$ and $v_{s g 4}$ only increased by a factor of 1369 and 1476 respectively. This indicates that, when the loading condition changes from quasi static to low loading rates, the loading rate effect on the early-stage crack velocity is almost three times stronger than its effect on the late-stage crack propagation; however, within the low loading rate range, when the loading rate increased by 34 , from $0.55 \mathrm{~mm} / \mathrm{s}$ to $17.4 \mathrm{~mm} / \mathrm{s}$, the increase factor from $v_{s g 1}$ to $v_{s g 3}$ remained practically the same (from 14.4 to 17.3). Within the high loading rate range, on the contrary, the crack advances with decreasing speed, and as loading rate increases, the crack propagation speed tends to be uniform, this is clearly seen from the pre and post-peak crack velocities. The maximum crack velocity reached approximately $20.6 \%$ of the Rayleigh wave speed.

Comparing the numerically-predicted two-stage crack propagation in [9], the experimentally observed pre- and post-peak velocities in Table 3 suggest that, at low loading rates, pre-peak crack propagation is stable in a sense that, continuous loading is necessary for continuous crack advancing, whereas post-peak one is unstable, since less external load leads to faster crack propagation. On the 
contrary, at high loading rates, impact loads result fast crack propagation from the very beginning, less external load at post-peak is accompanied by a slower crack extension.

\begin{tabular}{|c|c|c|c|c|c|c|c|}
\hline $\begin{array}{l}\text { Loading rate } \\
\qquad(\mathrm{mm} / \mathrm{s})\end{array}$ & $\begin{array}{c}\mathrm{v}_{\mathrm{sg} 1} \\
\mathrm{SG} 01-\mathrm{SG} 02 \\
(\mathrm{~m} / \mathrm{s})\end{array}$ & $\begin{array}{c}\mathrm{v}_{\mathrm{sg} 2} \\
\mathrm{SG} 02-\mathrm{SG} 03 \\
(\mathrm{~m} / \mathrm{s})\end{array}$ & $\begin{array}{c}\mathrm{v}_{\mathrm{sg} 3} \\
\mathrm{SG} 03-\mathrm{SG} 04 \\
(\mathrm{~m} / \mathrm{s})\end{array}$ & $\begin{array}{l}\mathrm{v}_{\mathrm{sg} 4} * \\
(\mathrm{~m} / \mathrm{s})\end{array}$ & $v_{\max } / v_{R}$ & $\begin{array}{c}\text { Pre-peak } \\
\mathrm{v}_{1} \\
(\mathrm{~m} / \mathrm{s}) \\
\end{array}$ & $\begin{array}{c}\text { Post-peak } \\
\mathrm{v}_{2} \\
(\mathrm{~m} / \mathrm{s}) \\
\end{array}$ \\
\hline $5.5 \times 10^{-4}$ & $1.9 \times 10^{-4}$ & $2.7 \times 10^{-4}$ & $7.3 \times 10^{-3}$ & $2.1 \times 10^{-3}$ & - & $2.3 \times 10^{-4}$ & $1.2 \times 10^{-3}$ \\
\hline $5.5 \times 10^{-1}$ & 0.78 & 0.73 & 1.05 & 3.1 & - & 0.58 & 0.73 \\
\hline $1.74 \times 10^{1}$ & 11.2 & 12.6 & 16 & 4.2 & - & 6.8 & 4.2 \\
\hline $8.81 \times 10^{2}$ & 292 & 250 & 208 & 138 & 14.4 & 344 & 171 \\
\hline $1.76 \times 10^{3}$ & 357 & 278 & 357 & 187 & 17.6 & 327 & 224 \\
\hline $2.64 \times 10^{3}$ & 417 & 417 & 387 & 200 & 20.6 & 417 & 275 \\
\hline
\end{tabular}

$* \mathrm{~V}_{\mathrm{SG} 4}$, crack velocity along the last $20 \mathrm{~mm}$ distance

Table 3: Average crack velocity evolution.

Loading rate effect on the size of FPZ. Figure 6 shows the method to determine the growth and development of the FPZ, taking the example of the loading rate at $2640 \mathrm{~mm} / \mathrm{s}$.

The upper half of the figure gives four strain histories recorded in the four strain gauges, with the time at peak strain $t_{\in \max }$ and the time when the strain relaxed to zero $t_{\in r 0}$ marked with filled squares and circles respectively. The time at peak load $t_{p k}$ is also shown to distinguish the pre and post-peak crack propagations. The lower half of Figure 6 shows the FPZ evolution with time during loading. Again, the crack velocity between two neighbouring strain gauges is the average, the variation of the velocity was not taken into account along this distance.

Table 4: FPZ size

\begin{tabular}{|c|c|}
\hline Loading rate $(\mathrm{mm} / \mathrm{s})$ & FPZ size $(\mathrm{mm})$ \\
\hline $5.5 \times 10^{-4}$ & $14-20-17$ \\
\hline $5.5 \times 10^{-1}$ & $25-47$ \\
\hline $1.74 \times 10^{1}$ & $17-21-14$ \\
\hline $8.81 \times 10^{2}$ & $23-21-16$ \\
\hline $1.76 \times 10^{3}$ & $16-19-15$ \\
\hline $2.64 \times 10^{3}$ & $18-21-16$ \\
\hline
\end{tabular}

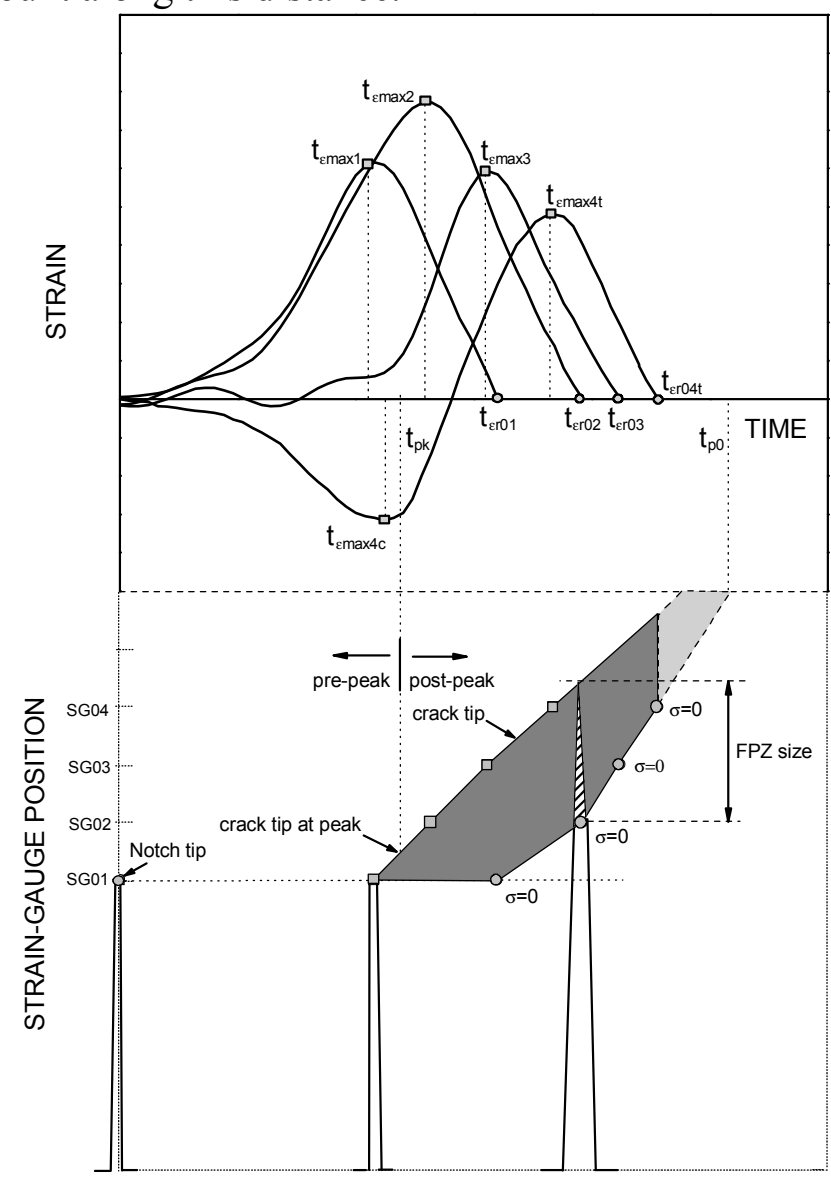

Figure 6: Methodology to estimate the development and growth of FPZ. Filled square symbols represent time at peak strain, whereas filled circles stand for time when the strain relaxed to zero. The upper half shows the strain histories recorded in the four strain gauges; the lower part illustrates the initiation and propagation of the main crack, where the shaded zone is the evolution of the FPZ during loading. The dashed-line-surrounded shadow indicates unconfirmed information due to lack of further measurements. Shown is the case of the loading rate at $2640 \mathrm{~mm} / \mathrm{s}$. 
The upper limit of the shaded zone shows the evolution of the cohesive crack tip, while the lower one represents the traction-free crack tip. For instance, in order to know the FPZ ended at SG02, i.e., when $\sigma=0$ is reached at $t_{\epsilon r 02}$, one needs to know the current location of the cohesive crack tip. From the upper part of Figure 6, we find the intersection point between the line $t=t_{\in r 02}$ and the upper limit of the dark shaded zone, the distance between this intersection point and SG02 is the sought FPZ size. Note that, the FPZ was not completely developed either within the first nor the last $20 \mathrm{~mm}$ due to boundary effects. Since four strain gauges were employed to measure the strain history, at most three FPZ sizes can be directly obtained, more values can be obtained through interpolation as in Figure 6. We nevertheless list only those directly obtained FPZ sizes in Tab. 4 separated by a dash "-" sign. If we exclude the possible boundary effects of the notch and final ligament of each specimen, the central FPZ size in Tab. 4 should be considered as the material FPZ size. Surprisingly, the FPZ size remained almost the same when the loading rate varied seven orders of magnitude. This is clearly different from NSC, in which the FPZ size actually decreased with loading rate, see Du et al. [10,11] and Wittman [6].

\section{Conclusions}

Using strain-gauge technology, employing a servo-hydraulic machine and a drop weight impact device, we have measured crack propagation velocities and the size of the FPZ for a HSC loaded over a wide range of loading rates, from $10^{-4} \mathrm{~mm} / \mathrm{s}$ to $10^{3} \mathrm{~mm} / \mathrm{s}$. The following conclusions can be drawn. (a) The peak load is sensitive to the loading rate. Under low loading rates, the rate effect on the peak load is minor, while it is pronounced under high loading rates. (b) The measured time to peak load $t_{p k}$, a measure of the initial CMOD rate, varied from $0.12 \mathrm{~ms}$ to $494 \mathrm{~s}$. (c) Unlike normal strength concrete, the FPZ size varied only slightly for loading rates of seven orders of magnitude. (d) Under low loading rates, the main crack advances with increasing velocity, the late-stage velocity is one-order higher than the early-stage one; the rate effect on the crack velocity is remarkable. At high loading rates, the main crack propagates with a decreasing crack velocity of several hundred $\mathrm{m} / \mathrm{s}$, the rate effect on crack velocity is minor. In addition the crack propagation velocity in the high loading-rate range reached $20 \%$ of the material's Rayleigh wave speed.

\section{References}

[1] Cedolin, L, Dei Poli, S., and Iori, I. Cement and Concrete Research, 13, pp. 557-567, (1983).

[2] Castro-Montero, A., Shah, S.P., and Miller, R.A., Journal of Engineering Mechanics, 116, pp. 2463-2484 (1990).

[3] Swartz, S.E., and Go, C.G., Experimental Mechanics, 24, pp. 129-134 (1984).

[4] Hu, X., and Wittmann, F.H., Journal of Materials in Civil Engineering, 2, pp. 15-23 (1990).

[5] Zhang, X.X., Ruiz, G., and Yu, R.C.: submitted to Strain, doi:10.1111/j.1475-1305.2008.00574.x. (2008).

[6] Wittmann, F.H., Sadhana - Academy Proceedings in Engineering Sciences, 27, pp. 413-423 (2002).

[7] Mindess, S., Canada Journal of Physics, 73, pp. 310-314 (1995).

[8] Hillerborg, A., Modéer, M., and Petersson, P.E., Cement and Concrete Research, 6, pp. 773-781, (1976).

[9] Zhang, X.X., Ruiz, G., and Yu, R. C., Journal of Materials in Civil Engineering, 20, pp. 544-551 (2008).

[10] Yon, J.H., Hawkins, N.M., and Kobayashi, A.S., ACI Materials Journal, 89, pp. 146-153 (1992).

[11] Du, J., Yon, J.H., Hawkins, N.M., Arakawa, K., and Kobayashi, A.S., ACI Materials Journal, 89, pp. 252-258 (1992). 